\title{
Menggali Makna Upacara Maulid Nabi di Padang Pariaman Sumatera Barat
}

\author{
Suryanti \\ Institut Seni Indonesia (ISI) Padang Panjang \\ Jalan Bundo Kanduang No 35 Padang Panjang
}

\begin{abstract}
The celebration of Maulid Nabi, known as "Dikie Maulid", is a tradition of Padang Pariaman society to celebrate the birth of prophet Muhammad (peace be upon him). The celebration is a routine activity which is believed having ethics and aesthetics values, so that it becomes a religious ritual of the society. This research used qualitative method in order to reveal the meaning of the people's behavior in various social situations. The result of the research shows that the celebration of Dikie Maulid is an Islamic religious expression with various activities such as malamang, mahanta kue, and bajamba, and it constitutes the identity of local culture of Padang Pariaman society. There are various art forms and elements in the ceremony of Maulid Nabi, among others are: literature, music, dance, and fine arts. The ceremony related to some events that are considered significant to the community.
\end{abstract}

Keywords: dikie maulid, malamang, mahanta kue, bajamba

\begin{abstract}
ABSTRAK
Perayaan Maulid Nabi, yang dikenal dengan "Dikie Maulid", adalah sebuah tradisi masyarakat Padang Pariaman untuk merayakan kelahiran nabi Muhammad (SAW). Perayaan ini merupakan kegiatan rutin yang dipercaya memiliki nilai-nilai etis dan estetis, sehingga menjadi sebuah ritual keagamaan masyarakat tersebut. Penelitian ini menggunakan metode kualitatif untuk mengungkap makna dari perilaku masyarakat dalam berbagai situasi sosial. Hasil dari penelitian menunjukkan bahwa perayaan Dikie Maulid merupakan sebuah ekspresi agama Islam dengan berbagai aktifitas, seperti: malamang, mahanta kue, and bajamba, serta menjadi identitas budaya lokal masyarakat Padang Pariaman. Terdapat berbagai bentuk dan unsur seni dalam upacara Maulid Nabi ini, di antaranya: sastra, musik, tari, dan seni rupa. Upacara ini berkaitan dengan berbagai peristiwa yang dipandang penting bagi komunitasnya.
\end{abstract}

Kata Kunci: dikie maulid, malamang, mahanta kue, bajamba 


\section{PENDAHULUAN}

Kehadiran upacara di suatu komunitas merupakan ungkapan perasaan tertentu yang berhubungan dengan bermacam-macam peristiwa yang dipandang penting bagi komunitasnya. Peristiwa-peristiwa itu ditransformasikannya ke dalam bentuk yang berstruktur lengkap dengan norma dan etika tertentu. Bentuk ungkapan yang muncul sewaktu melaksanakan ritual upacara tersebut juga bermacam-macam, sesuai dengan kepercayaan dan tradisi yang sudah dijalani secara turun temurun. Pada umumnya, hari kelahiran Nabi Muhammad saw disebut Maulid, sebuah kata yang juga berarti peringatan-peringatan yang diselenggarakan pada hari yang telah ditetapkan. Istilah lainnya adalah Milad (hari kelahiran, atau ulang tahun). Annemarie Schimmel (2000: 200) menjelaskan mawlud (dalam bahasa Turki modern ditulis mevlud) yang berarti puisi atau sastra umumnya. Sebagai Nabi yang dicintai umatnya, yang diyakini umat Islam telah menyelamatkan manusia di dunia dan akhirat, sewajarnyalah peringatan kelahirannya diperingati sebagai bentuk rasa cinta terhadap Nabi yang mulia.

Bulan Maulid di beberapa daerah disebut pula bulan maulud atau mulud. Dengan demikian tujuan utama tradisi ini adalah memperingati atau merayakan kelahiran Nabi Muhammad saw, caranya dengan mengingat kembali kisah kelahiran dan keteladanan Rasulullah, atau memujinya dengan berbagai kegiatan pengajian, pembacaan shalawat (dzikir) dan doa. Dalam perkembangannya, Maulid tidak hanya ditujukan sebagai peringatan khusus merayakan hari kelahiran nabi, tetapi ditujukan pula untuk berbagai keperluan, seperti upacara gunting rambut bayi, membawa turun mandi bayi, atau kegiatan upacara lainnya. Di Banjarmasin upacara Maulid dikaitkan dengan Baayun Anak, sementara di Pusat Keraton Solo, upacara Maulid Nabi dimeriahkan dengan upacara 'sekaten' (Hairus Salim, 2005: 17). 
Ritus Maulid ditandai pula dengan acara tahlil keraton yang berbeda dengan tahlil konvensional, karena model zikir tarekat varian yang diperkenalkan di Asia Tengah abad 16 dan $17 \mathrm{M}$.

Tradisi peringatan Maulid sebenarnya baru bermula pada abad ke-8 Masehi, lebih seabad setelah nabi sendiri wafat. Waktu itu rumah tempat nabi lahir, di Mekah, diubah menjadi sebuah oratorium oleh ibunda Khalifah Harun al Rasyid, Siti Zainab, dan orang-orang yang naik haji berbondongbondong mengunjungi tempat itu. Di situ mereka mendengarkan ceramah mengenai kehidupan nabi Abdul Hadi WM (2000: 49). Selanjutnya dijelaskan bahwa perayaan Maulid Nabi secara besar-besaran dimulai pada abad ke-10 di Mesir, di zaman Dinasti Fathimiyah (969-1171 M). Sebab keluarga kerajaan ini mengaku turunan langsung nabi melalui putri beliau, Fatimah. Meriahnya perayaan Maulid Nabi itu digambarkan oleh ahli sejarah Mesir abad ke 15; pada malam maulid para sarjana dan ulama mengambil peran uatama, dengan memakan manisan khususnya madu yang merupakan kegemaran nabi, sedangkan orang-orang miskin menerima sedekah memakan masakan dari domba, kambing dan sapi. Bermulanya peringatan Maulid Nabi di Pariaman berkaitan dengan perkembangan agama Islam oleh Syekh Burhanuddin ke daerah Ulakan Pariaman sekitar abad ke-XVI.

Tengku Syekh Idris, menjelaskan bahwa peringatan Maulid Nabi di Sungai Sariak merupakan tradisi yang dibawa oleh Engku Hitam dari Ulakan Pariaman. Sekitar abad XVIII. Perkembangan tradisi Maulid Nabi tidak hanya ke Sungai Sariak tapi juga menyebar hampir keseluruh pelosok Kabupaten Padang Pariaman. seperti Toboh, Sungai Geringing, dan Sicincin. Walaupun tradisi Maulid Nabi menyebar hampir keseluruh pelosok Pariaman, namun dalam pelaksanaannya mempunyai ciri dan cara pelaksanaan yang berbeda, sesuai dengan kebiasaan nagari masing-masing. Misalnya di daerah Sicincin perayaan Maulid Nabi juga diselingi dengan pesta kesenian Tabuik, yang tidak terdapat di nagari lain. Besar kemungkinan 
perbedaan ini juga dipengaruhi oleh kehadiran Ungku dengan aliran Thariqat yang dianut.

\section{PEMBAHASAN}

Masyarakat Padang Pariaman memiliki empat jenis seni tradisional yang sangat terkenal, yaitu Luambek, Indang, Gandang Tambua, dan Dikie Maulid. Keempat jenis seni ini sekaligus menjadi identitas kesenian Kabupaten Padang Pariaman yang sangat populer ke daerah lainnya di Minangkabau. Luambek, yakni sejenis seni bertarung (martial-art) yang didemonstrasikan oleh dua orang laki-laki dalam bentuk pola gerak silat yang tidak saling bersentuhan di antara keduanya dengan iringan musik vokal tradisional 'Dampeang.' Kesenian Indang, yaitu sejenis seni tutur yang berlatarbelakang Islami dengan teks cerita dan pantun. Penyajian teksnya didendangkan dalam irama khas Padang Pariaman dengan iringan musik perkusi rapa'i dan dilengkapi dengan gerakan-gerakan tari. Gandang Tambua, adalah sejenis musik perkusi ritmis yang ensambelnya terdiri dari tasa dan tambua. Sedangkan Dikie Muluik memiliki dua pemahaman: pertama, Dikie Maulid sebagai musik vokal Islami khas masyarakat Padang Pariaman Minangkabau yang teksnya bersumber dari kitab Syarafil Anam, dan ditampilkan pada perayaan Maulid Nabi; kedua, Dikie Maulid sebagai sebuah ritual yang bersifat religius dalam rangka memperingati hari kelahiran Nabi Muhammad saw oleh masyarakat Padang Pariaman, Sumatera Barat. Selain jenis kesenian tersebut, masyarakat Padang Pariaman juga memiliki ensambel musik tradisional Dikie Rabano dan Pencak Silat. Kesenian- kesenian tersebut dipertunjukan pada berbagai upacara adat dan ritual agama sesuai dengan konteks pertunjukannya masing-masing; di antaranya Alek Pauleh Tinggi, Alek Pauleh Randah, Upacara Tabuik, ritual Maulid Nabi, maupun dalam penyambutan tamu pemerintahan, dan lainnya. 


\section{Prosesi Pelaksanaan Upacara Maulid Nabi di Padang Pariaman}

Pelaksanaaan peringatan Maulid Nabi bagi masyarakat pada dasarnya mempunyai tujuan dalam rangka menjaga hubungan dengan Allah (hablum minallah) dan hubungan dengan sesama manusia (hablum minannas). Sebagai implementasi dari menjaga hubungan ini diwujudkan dengan merayakan peringatan Maulid Nabi. Pertimbangan lain untuk mengadakan peringatan Maulid Nabi misalnya dikarenakan sudah sekian lama satu kaum/suku tidak melaksanakan perayaan, ketika panen berhasil, agar terhindar musibah, atau bertujuan menghimpun dana untuk perbaikan masjid atau mushalla.

Oleh karena itu, perlu dilaksanakan perayaan peringatan Maulid sebagai sarana untuk menghimpun dana. Untuk mewujudkan tujuan ini dilakukan persiapan yang matang melalui musyawarah bersama oleh Ungku-ungku, ninik mamak, kaum ibu, dan anggota masyarakat lainya. Musyawarah dalam persiapan ini biasanya dilakukan jauh sebelum hari pelaksanaan, yakni sekitar 5-6 bulan, bahkan satu tahun sebelum perayaan dilaksanakan. Musyawarah biasanya akan didahului dengan pertemuanpertemuan kecil antara Ungku-Ungku dengan ninik mamak dan jamaah (babiliak ketek) di saat setelah shalat berjamaah di masjid atau di mushalla, kemudian bila dipandang sudah saatnya melaksanakan perayaan akan dibawa ke dalam musyawarah yang lebih besar (babiliak gadang). Dalam musyawarah ini Ungku dan Penghulu amat berperan dalam menggariskan tata cara pelaksanaan, menyangkut antara lain mengenai besar kecil acara, jadwal pelaksanaan, tukang dikie, undangan, dana yang dibutuhkan, teknis pengumpulan dana dan hal lain yang berhubungan dengan upacara. Musyawarah tidak hanya berlangsung satu kali, tapi mungkin sampai tiga empat kali pertemuan menjelang hari pelaksanaan. Setelah mendapatkan 
kesepakatan bersama, "bulek aie dek pambuluah, bulek kato jo mupakaik", maka dibentuklah kepanitiaan yang melibatkan seluruh unsur masyarakat dalam tingkatan kaum atau nagari.

Salah satu prosesi dari setiap upacara Maulid Nabi yang diselenggarakan masyarakat Padang Pariaman adalah malamang, baik pada tingkat nagari atau suku/ kaum. Kegiatan malamang berkaitannya erat dengan setiap kegiatan Maulid Nabi, dengan arti kata kalau tidak ada kegiatan malamang kegiatan Maulid Nabi tidak dilaksanakan. Untuk meringankan kebutuhan malamang yang biasanya dilaksanakan setiap tahun itu, biasanya bagi masyarakat petani jauh sebelum datang bulan maulid sudah menyiapkan setumpak sawah yang ditanam dengan pulut. Tidaklah heran kalau bulan perayaan Maulid Nabi dikenal sebagai bulan malamang. Setiap keluarga biasanya selalu menyemarakkan dengan membuat lemang sebanyak 100 sampai 200 batang, yang menghabiskan sekitar 70 sampai 90 liter beras ketan.

Proses pembuatan lemang dimulai sejak pukul 11.00. Dimulai dengan mempersiapkan talang (buluah) daun pisang, santan, merendam pulut, dan lain-lain. Diperlukan keahlian sendiri dalam membuat lemang, mulai dari memilih talang, mengisi talang, dan mendiangnya. Lemang mulai dibakar sekitar pukul 24.00, dibakar dengan mempergunakan kayu, tempurung dan sabut kelapa, yang sudah dipersiapkan beberapa hari sebelumnya. Kegiatan malamang biasanya baru selesai sekitar pukul $4.00-5.00$ pagi. Selain di rumah tangga masing-masing, di surau atau di masjid kaum masyarakat juga bergotong royong membuat lemang untuk menjamu tamu dan undangan. Untuk pekerja yang membuat lamang di masjid biasanya diupahkan kepada tukang masak yang didatangkan dari korong atau nagari lain yang tidak menyelenggarakan perayaan. Banyak atau sedikitnya lemang yang dibuat di masjid diperkirakan dengan jumlah undangan tamu yang 
akan hadir, biasanya sampai menghabiskan 600 - 700 liter pulut atau sekitar 1.600 batang lemang.

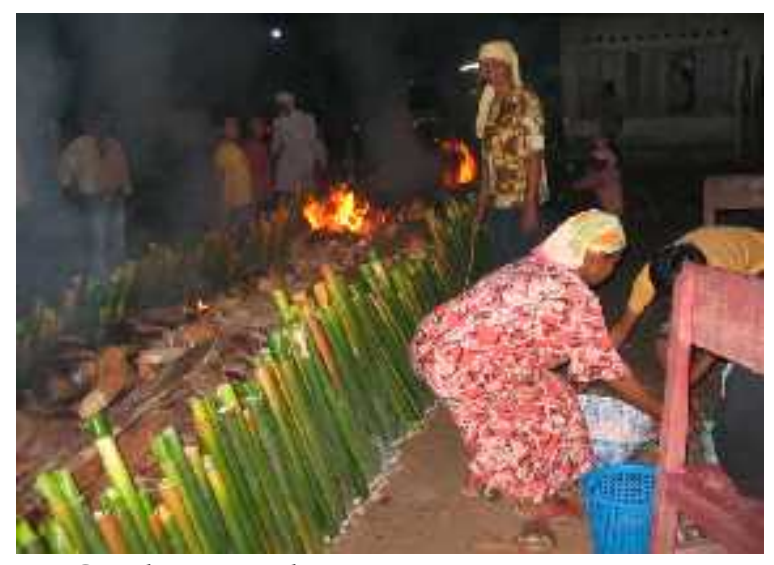

Gambar 1. Malamang

(Foto: Suryanti, 2008)

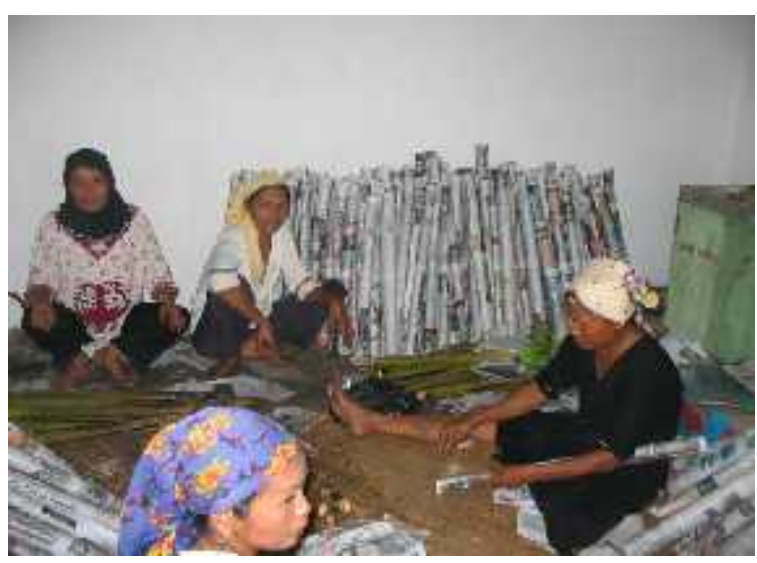

Gambar 2. Membungkus lamang (Foto: Suryanti, 2008)

Salah satu kewajiban bagi para menantu perempuan dalam upacara perayaan Maulid Nabi adalah mahanta kue untuak urang siak, ke mushalla/ masjid tempat perayaan berlangsung yang dilaksanakan pada sore hari pertama perayaan. Masing-masing menantu membawa empat sampai lima buah kue-kue bolu yang dihiasi dengan berbagai asesoris disusun di atas dulang atau keranjang sehingga menarik untuk dilihat. Di samping kue-kue bolu bagi yang mampu juga disertai dengan buah-buahan seperti jeruk, apel, pisang, dan minuman lain seperti fanta, sprite, coca-cola. Semua jedah ini disusun dengan rapi di atas dulang, kemudian ada pula yang disemarakkan dengan lampu hias. Sebelum diantarkan ke mushalla terlebih dahulu para menantu perempuan mengumpulkan masing-masing bawaan di rumah mertua, kemudian secara bersama menjunjung kue-kue tersebut ke mushalla/masjid. Acara mahanta kue ini berlangsung sejak sore hari pertama menjelang shalat Maghrib sampai menjelang tengah malam. Kue-kue ini dipajang dihadapan tukang dikie, dari arah mihrab sampai ke arah pintu masuk. Di beberapa tempat perayaan yang penulis saksikan, karena begitu banyaknya kue-kue yang dibawa oleh para menantu tersebut, hingga 
dipajang mulai dari ruang dalam arah depan hingga ke ruang beranda pintu masuk. Bagi yang datang lebih dahulu, kue yang dibawa akan dipajang pada ruang depan, sementara bagian yang datang belakangan tentu jedah yang dibawa akan terletak arah ke pintu masuk, kecuali kalau jedah yang dibawa tampak istimewa, panitia akan memajangnya pada ruang sebelah depan agar dapat dilihat tukang dikie, tamu, dan masyarakat yang datang. Bagi tokoh masyarakat seperti isteri Penghulu, isteri Wali Nagari atau orang yang dianggap berada (mampu) dan terpandang di tengah masyarakat tentu akan menyiapkan jedah (kue) dengan secara istimewa. Kalau diamati ternyata kue-kue yang diantarkan oleh masyarakat dalam setiap upacara Maulid Nabi, hanya sebagian kecil yang dimakan oleh tukang dikie dan tamu, sementara sebagian besar terutama kue-kue yang tampak istimewa hanya menjadi pajangan.

Pada hari kedua para menantu kembali ke masjid/mushalla untuk menjemput kue-kue yang sebagian besar tidak dimakan, kemudian membawa kembali ke rumah mertua. Kue-kue ini sebagian dibagikan kepada keluarga mertua, (bako anak), dan tetangga, atau kepada tamu yang datang dari jauh. Kesempatan mahantakan kue ini sekaligus juga bermanfaat sebagai acara manjalang antara anak pisang dengan bako, antara menantu dengan mertua.

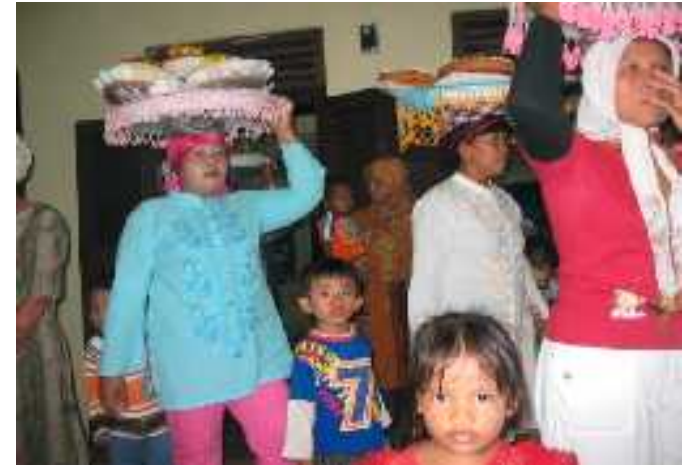

Gambar 3. Mahanta Kue (Foto: Suryanti, 2008)

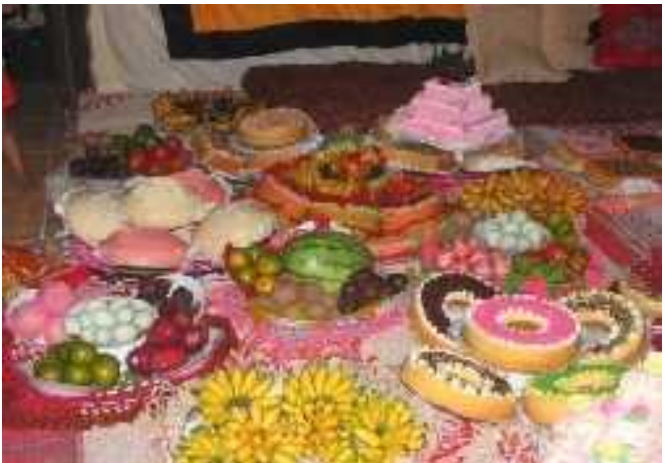

Gambar 4. Kue dan buah-buahan (Foto: Suryanti, 2008) 
Jamba adalah hidangan yang diletakkan di atas dulang yang terdiri dari nasi dengan lauk pauknya yang ditutup dengan tudung dan dalamak, terdiri dari nasi dengan lauk pauk; ayam singgang, ayam goreng, pangek ikan tongkol yang besar, gulai asam padeh gadang, telur bulat goreng, perkedel, terung goreng, goreng kacang panjang, patai balado. Sambal jamba jumlahnya ganjil boleh 5 piring, 7 piring, 9 piring, yang penting jumlahnya ganjil. Jumlah dan jenis lauk pauk yang dihidangkan dalam jamba tidaklah sama pada tiap desa. Nasi putih yang ada dalam jamba biasanya dibungkus dengan daun pisang sebanyak 10 bungkus kecil. Jamba dipersiapkan oleh setiap warga yang melaksanakan Maulid Nabi untuk dihantarkan ke surau atau masjid. Jenis dan ragam bervariasi disesuaikan dengan kemampuan masing-masing. Bagi yang mampu akan menyediakan jamba beragam, mulai dari satu ekor ayam singgang sampai goreng atau pangek ikan besar, di samping ragam sambal lainnya. Bagi yang kurang mampu mungkin hanya membawa satu piring goreng telur dan terung goreng. Jamba disusun bertingkat dalam satu tempat yang disebut umah-umah lalu dihantarkan ke masjid menjelang shalat Dzuhur.

Bajamba menjadi ajang untuk saling unjuk kekayaan dengan berlomba-lomba membuat jamba yang lebih besar. Bahkan bisa dikatakan bahwa status sosial juga menentukan besar kecilnya jamba yang dibawa. Semakin tinggi statusnya di mata masyarakat ia juga akan membuat jamba yang lebih besar, begitu juga sebaliknya. Dari penuturan tersebut kita juga bisa melihat bahwa bagi sebagian lainnya, acara bajamba ini menjadi sebuah kegiatan yang menjurus pada riya. Kegiatan bajamba yang diadakan di mesjid menjadi sebuah kesempatan untuk bertemu dan bercerita dengan teman-teman yang jarang bertemu, termasuk yang pulang dari rantau, ini dapat dipandang merupakan proses sosialisasi nilai-nilai pada generasi yang lebih muda. 
Jika kita melihat melalui teori dramaturgi Goffman, ternyata memang terdapat skenario yang harus dilakonkan oleh setiap individu masyarakat. Seorang isteri penghulu akan bersikap dan menyediakan jamba sesuai dengan statusnya sebagai seorang penghulu. Ketika hal itu tidak mereka kerjakan sesuai dengan aturannya maka mereka akan menjadi bahan perbincangan di tengah masyarakat. Ketika mereka melaksanakannya sesuai dengan keinginan masyarakat mereka juga akan mendapat penghargaan yang tinggi di mata masyarakat tersebut. Pernyataan Goffman benar dengan mengatakan bahwa individu akan bertingkah laku sesuai dengan pola perilaku yang telah ada. Bisa dilihat bahwa kegiatan bajamba membentuk sebuah pola yang harus diikuti oleh individu masyarakat. Mereka tidak perlu berfikir akan melakukan apa karena lakon mereka telah disediakan oleh masyarakat.

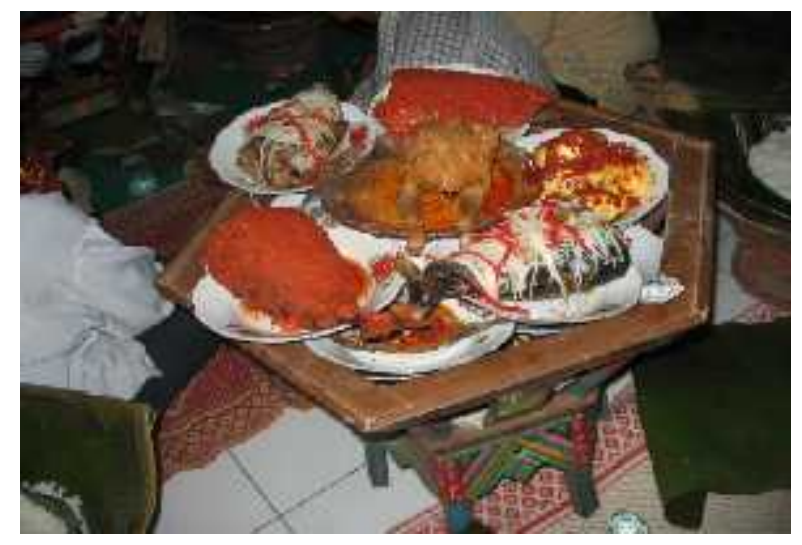

Gambar 5. Jamba (Foto, Suryanti:2008) (Foto: Suryanti, 2008)

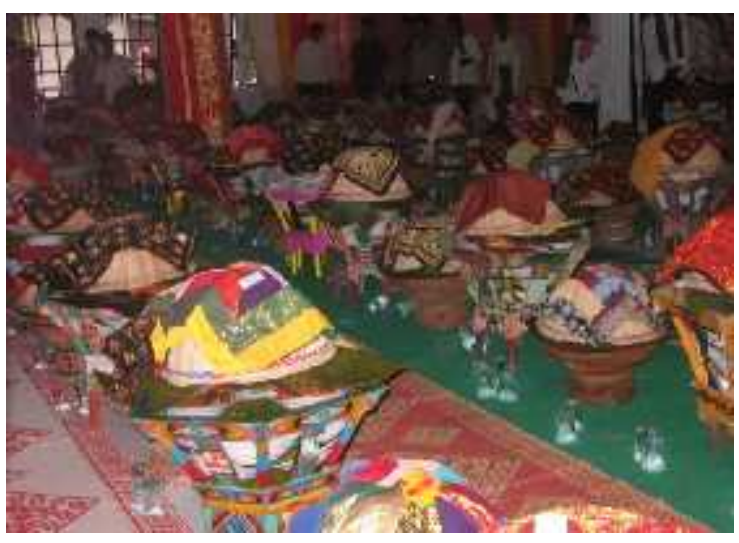

Gambar 6. Jamba di atas Umah-umah (Foto: Suryanti, 2008)

\section{Badikie (berdzikir)}

Istilah kata 'dikie' berasal dari bahasa Arab zikra, yang berarti mengingat, (Allah). Muhammmad Arifin Ilham dalam buku "Panduan 
Lengkap Zikir dan Doa", membagi "zikir" dalam bebeapa bentuk; (a) zikir qalbiyah (ihsan) yakni hati yang senantiasa mengingat Allah; (b) zikir aqliyah yakni kemampuan menangkap bahasa Allah dibalik setiap gerak alam semesta; (c) zikir lisan yakni buah dari zikir hati dan akal, dan (d) zikir amaliyah, perwujudan dari ketiga bentuk di atas ke dalam kehidupan yang sesungguhnya yakni taqwa, (2005: 4-6). Merujuk pada pendapat di atas, dapat difahami bahwa badikie adalah satu proses pembersihan hati dan diri kita dari setiap noda-noda kehidupan agar dapat hidup dalam kesucian yang diridhai Allah (rabbunallah). Badikie yang dilakukan oleh tukang dikie dalam perayaan Maulid Nabi di Sungai Sariak mengingat Allah dengan cara memuji dan bersalawat kepada Rasulullah, baik melalui lisan maupun hati. Syair-syair dikie yang dikumandangkan atau dinyanyikan adalah mengisahkan peristiwa perjuangan Nabi Muhammad saw dan para sahabat beliau, serta syair-syair yang memuji Allah. Syair-syair yang dialunkan ada yang dalam bahasa Arab namun ada pula yang disampaikan dalam Bahasa Indonesia dan Bahasa Minang. Contoh syair yang dialunkan oleh Tukang Dikie, sebagaimana berikut:

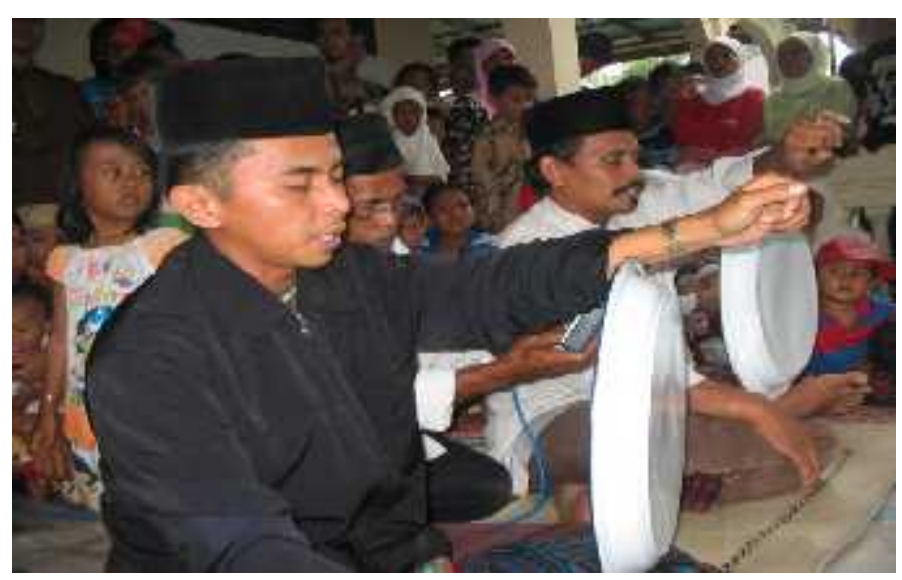

Gambar 7. Kesenian Salawat Dulang (Foto: Suryanti, 2008) 
Bahasa Arab:

Allahu-allahu-Allahu kam Allahu

Allahu kam maulai kam lahuulai m

Allahu-allahu-Allahu minmuk illah

Minmuk maulai mukraman

Maulai Allahu kam 'athallahu ya wa firaat

Allahu-allahu-Allahu kam Allahu

Kam maulai kam rawat

Allahu-allahu 'anmullahu 'anhu ustqat

Maulai Allahu ya Kullu 'il Allahu min

Allahu ya waajib.

Allah-Allah ya Nur

Allah ya Nur maulai nur muha

Allah Allah Aqradha Muhammad

Maulai shallallahu

Mulai Allahu ya La ialaha Ilallahu

Huillahu ya La Ilaha Ilallah.

Bahasa Indonesia:

Allah-Allah dari Mekah ke Medinah

Allah-Allah semalam nabi di dalam laut

Allah-Allah menangis anaak Siti Patimah

Allah ya Rabbana ya Rasulullah

Allah menangis anak Siti Patimah

Allah mendengar suara lai Nabi Daud

Allah Allahu ya Nabi junjungan kami

Allah bari syafaat hamba $\mathrm{Mu}$ ini

Allah tidak yang lain diharap lagi

Allah ya rabbana ya Rasulullah

Allah tidak yang lain diharap lagi

Allah Rasulullah penghulu kami.

Melalui syair dalam peristiwa Maulid mereka meyakinkan diri bahwa tanpa perjuangan nabi dan para sahabat, tak mungkin Islam akan berjaya atau tak mungkin Islam ada, sebab agama Islam hanya diturunkan kepada Nabi Muhammad saw. Dalam upacara Maulid dapat pula dilihat berbagai bentuk dan unsur seni, seperti seni sastra dan seni suara. Kisah perjuangan 
Rasulullah tersebut yang dikemas dalam bentuk seni ini tanpa disadari oleh tukang Dikie menghadirkan rasa haru yang dalam sehingga tak jarang tanpa disadarinya mereka sampai meneteskan air mata.

Bagi mereka kegiatan badikie sekaligus sebagai ungkapan rasa terima kasih dan rasa syukur terhadap Allah SWT, yang telah melimpahkan rahmat dan hidayah Nya kepada umat manusia, mereka membayangkan betapa kecilnya dia dihadapan Allah. Badikie (zikir), dilakukan oleh para tukang dikie yang biasanya didatangkan dari korong lain di sekitar Pariaman. Tukang Dikie ini datang berpasangan (dua orang), biasanya sampai mencapai 10 atau 12 pasang yang dipesan dari kampung lain di seputar Pariaman. Badikie biasanya dimulai setelah para undangan mulai datang sekitar pukul 21.00 berlangsung sampai menjelang waktu shubuh. Setelah istirahat beberapa jam, sekitar pukul 09.00 dilanjutkan sampai menjelang waktu shalat Ashar.

Dalam mengakhiri badikie sekitar pukul 15.00 - 16.00, pemain dikie menyajikan dikie maulid yang agak berbeda dengan penyajian malam sebelumnya. Pemain dikie menyajikan sambil berdiri, bergoyang ke kiri dan ke kanan dengan intens. Ruang mushalla/ masjid tempat pemain dikie disemprot dengan parfum dan wangian-wangian. Waktu-waktu ini dipandang dan dirasakan sebagai saat-saat ruh Rasulullah dan para Malaikat turun ke bumi menyaksikan dan memberi keberkatan kepada umat manusia.

Pada akhir lagu ditutup dengan bacaan Assalamualaikum dan diiringi dengan doa yang diikuti secara bersama oleh hadirin. Dengan demikian selesailah upacara peringatan Maulid Nabi, dan sebagai acara mewujudkan rasa syukur dengan telah selesainya acara peringatan maulid para undangan dan hadirin makan bersama. Pada waktu tukang dikie pulang ke rumah masing-masing, sebagai imbalan yang diberikan kepada tukang dikie yaitu diberikan lamang 4 batang, kain sarung, dan amplop berisi uang 
besarnya sesuai dengan kesepakatan misalnya Rp 200.000 (dua ratus ribu rupiah).

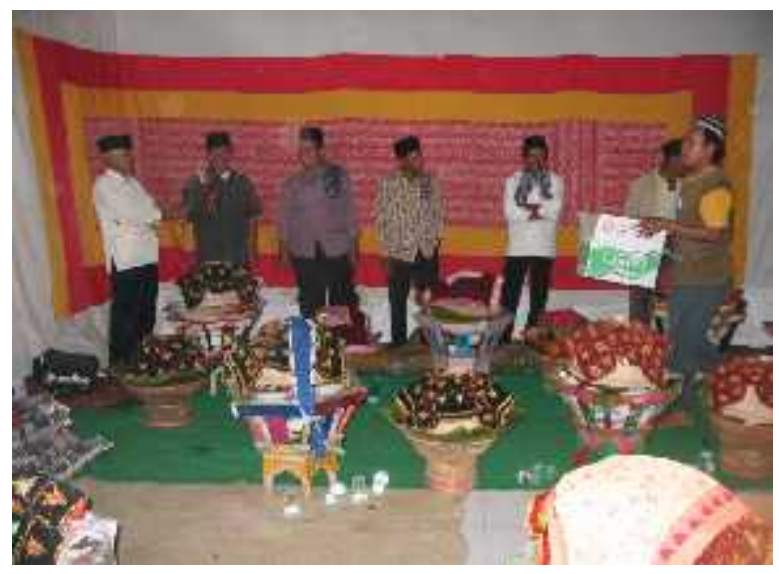

Gambar 8. Badikie (Foto: Suryanti, 2008)

\section{Makna Budaya Maulid Nabi bagi Masyarakat Padang Pariaman}

\section{a. Makna Malamang}

Kegiatan malamang di nagari Sungai Sariak tidak hanya ditemui dalam upacara peringatan Maulid Nabi, tapi juga dalam upacara peringatan hari besar Islam lainnya, seperti dalam memeriahkan Hari Raya Idul Fitri, Hari Raya Idul Adha, maupun pada acara pernikahan. Pada konteks ini kegiatan malamang hanya dilakukan dalam jumlah kecil, terbatas untuk keluarga. Kegiatan malamang dalam jumlah yang besar hanya dilakukan pada upacara peringatan Maulid Nabi, dengan arti kata kegiatan malamang sudah merupakan simbol peringatan Maulid Nabi bagi masyarakat Sungai Sariak.

Proses pembuatan lamang dimulai dengan pengambilan talang (buluah) yang dilakukan oleh anggota masyarakat secara bersama-sama, baik secara berkaum, berkeluarga ke ladang masing-masing atau ketempat yang sudah ditentukan. Talang yang ditebang dipilih sesuai dengan kebutuhan yang cocok untuk memasak lemang, dengan pedoman "tuo alun, mudo talampau, kaciek tidak gadangpun tido, sadang elok dipandang urang", 
maksudnya talang dipilih yang tidak terlalu tua, sudah melewati umur batas muda, tidak terlalu kecil dan tidak pula terlalu besar, biasanya panjang sekitar 60-70 cm, dengan diameter lebih 3-5 cm. Bila talang yang dipilih terlalu tua akan mudah terbakar, menyebabkan lemang hangus, sebaliknya bila talang terlalu muda akan mudah pecah waktu didiangkan. Ukuran yang sedang agar bagus atau pantas dilihat orang. Hal ini menurut Tengku Idris , salah seorang pemuka kaum di Sungai Sariak mengandung arti: segala sesuatu dilakukan dengan sederhana, tidak menyolok, kesederhanaan itu menggambarkan kepribadian seseorang, inilah antara lain makna yang terkandung dalam pembuatan lemang (malamang).

\section{b. Makna Badikie}

Badikie merupakan puncak peringatan Maulid Nabi di Pariaman umumnya. Badikie dilaksanakan di malam hari, sehari setelah acara malamang. Saat malam badikie inilah semua jamba diantar dan disusun di mesjid. Dikie dinyanyikan oleh Tukang Dikie yang biasanya didatangkan dari kampung lain, yang biasanya terdiri atas 2 orang satu pasangan, yang terkadang sampai dengan 10-12 pasang. Dikie merupakan syair puja-puji terhadap Nabi Muhammad saw yang melekat di hati masyarakat Padang Pariaman. Kesenian Badikie punya makna yang berbeda-beda, bagi masyarakat antara lain: 1) badikie punya nilai ibadah sebagai jalan mengingat Allah, 2) merupakan kesempatan masyarakat untuk mengumpulkan dana guna pembangunan fasilitas umum, seperti mendirikan mesjid/musholla, 3) bagi kaum muda, ini sebuah kesempatan untuk pergi dengan temantemannya di malam hari, 4) selain itu ada juga yang memandang badikie sebagai kesenian yang hanya ada di Pariaman, 5) bagi aparat Pemerintah Daerah, kegiatan ini merupakan kesempatan pula untuk bertatap muka dengan masyarakat. 


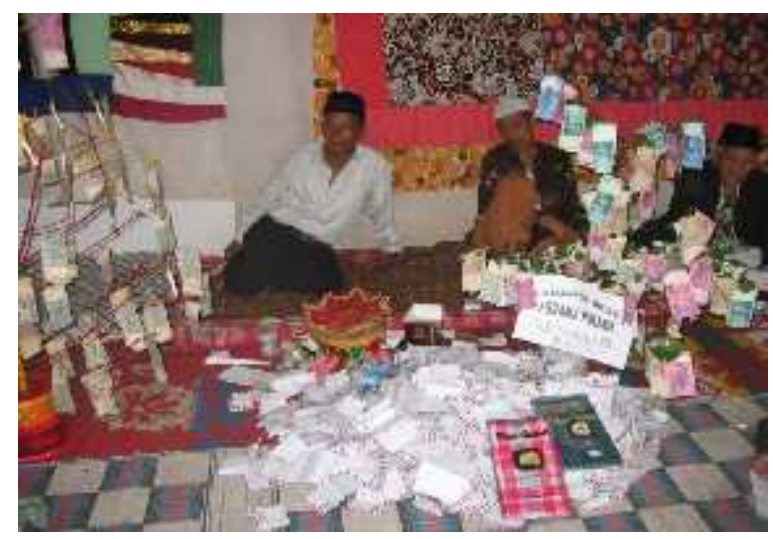

Gambar 9. Sumbangan

(Foto: Suryanti, 2008)

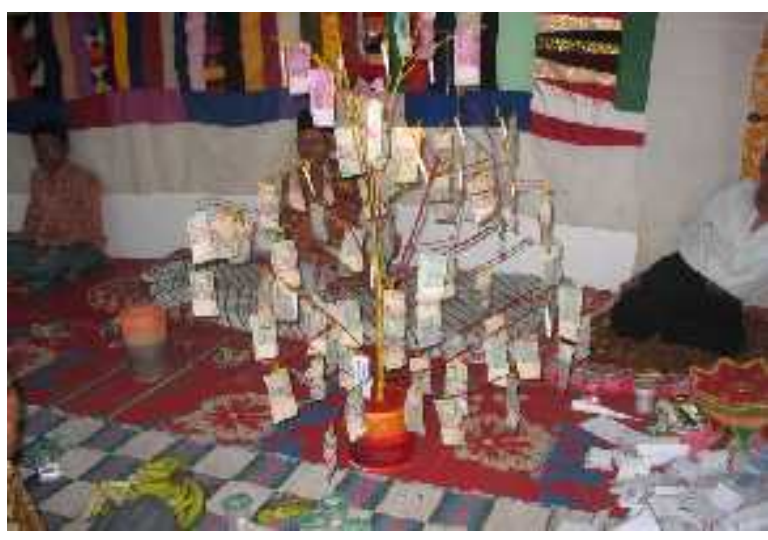

Gambar 10. Gajombang Pith

(Foto: Suryanti, 2008)

\section{PENUTUP}

Salah satu alasan masyarakat Padang Pariaman melaksanakan perayaan Maulid Nabi di samping memperingati kelahiran Nabi Muhammad adalah mengumpulkan dana untuk pembangunan masjid/surau, atau TPA. Perayaan Maulid Nabi dilaksanakan secara bergiliran, antara satu mushalla/masjid baik pada tingkat korong maupun nagari. Untuk itu perlu diadakan pengaturan jadwal, misalnya bila pada tahun ini kaum (pasukuan) A melaksanakan perayaaan, maka tahun depan suku B yang melaksanakan. Hal ini dilakukan karena masyarakat yang diharapkan untuk hadir dan memberikan sumbangan adalah masyarakat yang bertempat tinggal di sekitar mereka. Istilah ini disebut dengan istilah julo-julo atau saling membantu secara bergotong royong, barek samo dipikue, ringan samo dijinjiang. Tradisi ini telah sama-sama dipahami oleh masyarakat. Apalagi biaya yang harus disediakan dalam setiap perayaan tergolong mahal, rata-rata di atas 20-30 juta rupiah.

Cara lain penyerahan sumbangan yang terasa unik adalah dengan menjepitkan uang lembaran uang kertas pada ranting kayu yang ditata sedemikian rupa, ini disebut gajombong. Lembaran uang yang 
diselipkan biasanya mulai dari uang seribu, lima ribu, sepuluh ribu, sampai dengan lembaran lima puluh ribu rupiah. Satu gajombong bisa bernilai dua ratus sampai tiga ratus ribu rupiah. Sumbangan dalam bentuk gajombong biasanya diberikan oleh tokoh masyarakat terpandang, baik yang berada di kampung halaman maupun dari rantau, ataupun dari kelompok suku lain yang ada di kampung. Berangkat dari pengamatan terhadap tata cara pelaksanaan pencarian dana, tampak bahwa semangat persatuan, dan saling bantu antara individu dengan individu lain, antara satu suku dengan suku lain, tetap hidup melalui perayaan Maulid Nabi.

\section{DAFTAR PUSTAKA}

Abu Mu.awiyah Hammad.

2007 "Studi Kritis Perayaan Maulid Nabi", Al-Maktabah Al-Atsariyah, Ma'had TanwirAs-Sunnah, PKG, Gowa.

Asril Mukhtar.

2005 "Tradisi Maulid Pariaman." Majalah Gong 69/II.

Bustamar.

1990 "Kefanatikan Pengikut Ajaran Thariqat Syathariyah Kepada Imam Ditinjau Dari Ajaran Islam." Skripsi. Batusangkar: STAIN.

Geertz, Clifford.

1992 Tafsir Kebudayaan. Yogyakarta: Kanisius.

Hamersima, Harry.

1982 Eksistensi dan Trandensi dalam MetafisikaKarl Jasfers dalam Manusia Multi Dimensional: Sebuah Renungan Filsafat, Jakarta, Gramedia

Haviland, William A.

Antropologi. Edisi ke-4 Jilid I Cetakan Ketiga. terj. RC. Soekadijo. Jakarta: Erlangga. 
Kaemmer, John E.

1993 Music in Human Live Antropological Perspective on Music. Austin University of Texas Press

Kuntowijoyo.

2001 Muslim Tanpa Masjid. Jakarta: Mizan.

Kuper, Adam \& Jessica Kuper.

2000 Ensiklopedi Ilmu-ilmu Sosial. Edisi kedua. Jakarta: PT Raja Grasindo Persada.

Lauer, Robert H.

1993 Perspektif tentang Perubahan Sosial. (catatan kedua). terj. Alimaudan, PT. Rhineka Cipta.

Lincoln, Y. Vonnadan Egon G. Guba.

1985 Naturalisme Inquiry. Beverly Hills. London: Sage Publication.

LKAAM.

1981 Pelajaran adat minangkabau: Sejarah dan Budaya Padang: Tropic Offset Printing, 1981.

Mahmud Yunus.

1971 Sejarah Islam di Minangkabau Sumatera Barat.

Markhamah.

2000 Transformasi Budaya Spiritual ke Budaya Material, dalam

Transformasi Budaya. Surakarta: Muhammadiyah University Press.

Nadirsyah, Hosen.

2007 "Pesantren dan Tradisi Maulid." diakses dari Internet tanggal 24 Januari 2007.

Rustandi, Anton.

2005 "Perayaan Sang Nabi." Majalah Gong 69/VII.

Schimmel, Annemarie.

2000 Dan Muhammad Utusan Allah. Penerbit Mizan

Syarief, Ichlas. 
1992

Dikie Rabano di Kanagarian Jaho Kecamatan X Koto Tanah Datar, Penelitian.

Syeikh Shafiyurahman al Mubarakfury.

2003 "Sirah Nabawiyah", Pustaka Al Kautsar, Jakarta

Usman Al khaibani.

1980 "Duratun Nasihin", Penerbit Al Munawar, Semarang

Yunus, Mahmud.

1971

Sejarah Islam di Minangkabau Sumatera Barat. 